\title{
Medical Genetics Core Competence Survey in Pediatric Residents at McMaster University Medical Center
}

\author{
By Chumei $\mathrm{Li}^{*}$
}

\begin{abstract}
Knowledge about pediatric residents' core competency in medical genetics can help refine educational process and emphasis. Pediatric residents enrolled in McMaster University Medical School Postgraduate Program and rotated through Clinical Genetics Division were assessed for their Core Competency in Genetics at McMaster Children's Hospital, a tertiary care academic hospital. The residents showed a consistent pattern of strength and weakness in their core competency in genetics. Their scores ranged from 60-88/100 for overall competency, with highest scores in pedigree construction and description of specific genetic syndromes, while the lowest scores were in genetic laboratory investigations. Pediatric residents have a much more solid base in clinical training than in understanding genetic laboratory investigations and may benefit from more content in this particular area in their future curriculum.
\end{abstract}

Keywords: Core competency, Curriculum, Laboratory investigation, Medical genetics, Pediatric residents.

\section{Introduction}

Physicians' overarching competencies in genetics include taking a family history, assessing genetic risks, ordering appropriate genetic tests and interpreting the results, as well as the ability to counsel patients and families in regards to their genetic risks and test results (Kaye and Korf 2013). Pediatricians are often involved in the care of children with a genetic diagnosis or a suspected genetic diagnosis. However, there have been no systematic assessment of their core competency in genetics in our service area, nor of the pediatric trainees in our training program at McMaster University Medical School. As the knowledge of pediatric resident's core competency in medical genetics can be a surrogate marker for community pediatricians, and can be helpful in constructing their training curriculum as well, I took to ascertain the core competency of the pediatric residents during their rotation through clinical genetics.

\section{Methods}

A set of 10 questions designed to assess Core Competency in clinical genetics were administered to pediatric residents in postgraduate year 3 (PGY3) as they rotated through clinical genetics at McMaster University

\footnotetext{
${ }^{*}$ Director, Clinical Genetics Program, McMaster University Medical Center, Canada.
} 
Medical Center/McMaster Children's Hospital, an academic tertiary healthcare center. About 10 residents each year did their mandatory block of clinical genetics rotation of 3-4 weeks in duration. For a period of 5 and a half years, a total of 46 residents were tested on their core competency in clinical genetics. During that time period, all questions remained the same except for question \#9 "clinical indications for chromosome studies". For the first three and a half years it was "clinical indications for chromosome karyotype". This was changed two years ago to "clinical indications for chromosome microarray".

The questions in the core competency test include:

1. Pedigree construction.

2. Reproductive risk assessment based on population carrier frequency.

3. Baseline assessment of/approach to the dysmorphic child.

4. Genetic counseling on Newborn Screen Positive Results.

5. Baseline assessment of/approach to the child with tall stature.

6. Baseline assessment of/approach to the child with short stature.

7. Assessment of an infant with a suspected overgrowth syndrome.

8. Common syndromes -6 common syndromes' clinical features and their genetic investigations.

9. Interpretation of karyotype results.

10. Clinical indications for chromosome studies.

\section{Results}

A total of 46 residents in pediatrics took the Core Competency Test. All were PGY3. Data from PGY2 Neurology or PGY4-5 Developmental fellows or residents of other subspecialties were excluded from this data set.

Results are presented in Tables 1-3 under categories of 1) pedigree, risk assessment and clinical approach to certain common presenting problems in clinical genetics in the pediatric population; 2) descriptive prose of selected common genetic syndromes and their investigations; 3) questions dedicated to laboratory investigations routinely employed in clinical genetics.

A clear pattern emerged. The majority of the residents handled clinical assessment/approach questions satisfactorily, but no one could satisfactorily interpret two sample karyotype reports and their clinical significance. While most knew the clinical features of Noonan syndrome, few knew how to investigate this condition.

Equally of significance, for Sotos syndrome and Prader-Willi syndrome, a fair number of residents answered "microarray", which was partially right but in fact could be a choice by default, a reflection of microarray test's seminal importance in genetic investigation, instead of a reflection of the resident's true understanding of the underlying molecular mechanism for these conditions. This suspicion was supported by how a large number of residents had chosen "microarray" to test for Noonan syndrome and Fragile X syndrome. 
Table 1. Results on Pedigree Construction, Risk Assessment, Dysmorphism Assessment and Abnormal Growth Assessment

\begin{tabular}{|c|c|}
\hline Questions & Number of residents giving correct answers \\
\hline Pedigree & $42 / 46$ \\
\hline Risk assessment & $33 / 46$ \\
\hline Dysmorphic child & Out of 6 sub-questions \\
assessment & $5 / 6$ correct answers $1 / 46$ \\
6 sub-questions & $4-3 / 6$ correct answers $41 / 46$ \\
& $2 / 6$ correct answers $3 / 46$ \\
& $1 / 6$ correct answers $1 / 46$ \\
\hline Newborn Screen counseling & $40 / 46$ \\
\hline Tall Stature & $40 / 46$ partial \\
& $0 / 46$ complete \\
\hline Short Stature & $35 / 46$ partial \\
& $7 / 46$ complete \\
\hline Overgrowth & $38 / 46$ partial \\
& $0 / 46$ complete \\
\hline
\end{tabular}

Table 2. Results on Questions Related to Common Genetic Syndromes

\begin{tabular}{|c|c|c|}
\hline $\begin{array}{c}\text { Questions on Common } \\
\text { syndromes }\end{array}$ & \multicolumn{2}{|c|}{ Number of residents giving correct answers } \\
\hline & Clinical features & $\begin{array}{c}\text { Laboratory } \\
\text { Investigations }\end{array}$ \\
Noonan & $44 / 46$ & $2 / 46$ \\
Williams & $40 / 46$ & $26 / 46 \mathrm{partial}$ \\
Sotos & $38 / 46$ & $26 / 46 \mathrm{partial}$ \\
Fragile X & $44 / 46$ & $26 / 46$ \\
Prader-Willi & $43 / 46$ & $30 / 46 \mathrm{partial}$ \\
Down & $44 / 46$ & $43 / 46$ \\
Fetal Alcohol & $45 / 46$ & \\
\hline
\end{tabular}

Table 3. Results on Laboratory Investigations

\begin{tabular}{|c|c|}
\hline Questions on genetic investigations & $\begin{array}{c}\text { Number of residents giving } \\
\text { correct answers }\end{array}$ \\
\hline Karyotype interpretation & $0 / 46$ \\
\hline $\begin{array}{c}\text { Clinical indications for chromosome } \\
\text { karyotype or chromosome microarray }\end{array}$ & $24 / 46$ \\
\hline
\end{tabular}

\section{Discussion}

Although individual genetic syndromes are rare, collectively these rare syndromes are not rare, affecting a sizable pediatric population. A core competency in clinical genetics will certainly benefit the physician who looks after patients with a rare genetic condition, or who needs to rule in or rule out a suspected genetic condition. 
Clinical laboratory tests in genetics are fast evolving. With the availability of whole genome array and whole exome sequencing on a clinical basis, primary care physicians have a need to be able to choose the appropriate test and to be able to interpret the results.

Published literatures indicated that family physicians and general practitioners believe genetics care to be important, but felt underprepared to deal with genetic conditions (Carroll et al. 2009, Houwink et al. 2012). Literatures on Primary care Pediatricians are limited (Chen et al. 2008, Rinke et al. 2014). Medical genetic education is an area that has been looked into to improve the educational process (Bupp et al. 2015), but medical genetics core competency in pediatric trainees has not been systematically evaluated. Approximately $50 \%$ of clinical geneticists come from a background training in pediatrics (Bupp et al. 2015), reflecting the close link between clinical practice in pediatrics and clinical genetics.

The aim of this study was to assess general core competencies of the pediatric trainees and to identify areas of strength as well as areas suitable for targeted resource deployment and curriculum development.

Over the course of five and a half years, a total of 46 PGY3 pediatric residents enrolled in the Postgraduate Program at McMaster University were tested on a set of 10 questions measuring core competency in clinical genetics. A very distinct pattern emerged from this study. Most of the residents demonstrated strong clinical knowledge and skills, both in the Core Competency Test in genetics, as demonstrated in their overall scores for Questions 1-7, part I of Question 8, and through bedside assessment (mainly through mini-Clinical Evaluation Exercise, data not included).

A more careful look at the scores on part II of Question 8, however, raised the doubt that the partially correct answers may not have truly reflected the trainee's correct choice of microarray for the conditions concerned. This doubt is supported by the indiscriminate use of microarray by a large number of residents as the genetic test of choice for Fragile $\mathrm{X}$ syndrome and Noonan syndrome. Microarray appeared to be the default or reflex choice for unknown genetic investigation, indicating a gap in understanding the underlying genetic mechanisms of different syndromes, and consequent choice of genetic tests.

Additionally, the trainees' performance on Questions 9 - 10 also reflected such a gap in choice of laboratory genetic tests.

Although this data set is not large, and included only PGY3 residents at one academic training center, and therefore may not be representative of residents of other specialties, of more advanced training or in other training centers and programs, it is equally possible that this is not the exception to the rule. The consistency of the scores over the course of more than 5 years strongly argues for a pattern of undeniable strengths and weakness.

Based on this data set, the need for more content education in genetics for pediatric trainees at McMaster is identified with targeted emphasis placed on understanding the underlying genetic mechanisms of different syndromes and choice of investigations as well as interpretation of the results. 


\section{References}

Bupp C, Demmer L, Saul R (2015) Surveying the current landscape of clinical genetics residency training. Genetics in Medicine 17: 386-390.

Carroll JC, Rideout AL, Wilson BJ, Allanson JM, Blaine SM, Esplen MJ, Farrell SA, Graham GE, MacKenzie J, Meschino W, Miller F, Prakash P, Shuman C, Summers A, Taylor S (2009) Genetic education for primary care providers: improving attitudes, knowledge, and confidence. Canadian Family Physician 55(12): e92-e99.

Chen MJ, Holt CL, Lose EJ, Robin NH (2008) The use by Alabama pediatricians of genetics consultation in the evaluation of developmental delay. American Journal of Medical Genetics A 146A(4): 421-425.

Houwink EJ, Henneman L, Westerneng M, van Luijk SJ, Cornel MC, Dinant JG, Vleuten CV (2012) Prioritization of future genetics education for general practitioners: a Delphi study. Genetics in Medicine 14(3): 323-329.

Kaye C, Korf B (2013) Genetic literacy and competency. Pediatrics 132(Suppl. 3): S224-S230.

Rinke ML, Mikat-Stevens N, Saul R, Driscoll A, Healy J, Tarini BA (2014) Genetic services and attitudes in primary care pediatrics. American Journal of Medical Genetics A 164A(2): 449-455. 
